REVIEW ARTICLE

\title{
Radiofrequency Ablation as a Treatment Modality for Hypertrophic Cardiomyopathy
}

\author{
Kareem M. M. Ibrahim, MBBCH* \\ Faculty of Medicine, Alexandria University, Egypt
}

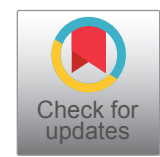

*Corresponding author: Kareem M. M. Ibrahim, MBBCH, Faculty of Medicine, Alexandria University, 61 Ismail Sery st., Smouha, Alexandria, Egypt, Tel: (002)01063727703 - (002)-034292012

\begin{abstract}
Hypertrophic cardiomyopathy is one of the major causes of cardiac death that affects 1 in every 500 persons worldwide. Surgical myectomy and alcohol septal ablation have been the gold standard well established procedures for the treatment of this condition. Starting 2004 a new procedure, radiofrequency septal ablation, has been applied and showed significant improvement in the NYHA classification as well as the left ventricular outflow tract (LVOT) gradients of these patients. With overall less complications, as compared to the surgical myectomy and the alcohol septal ablation, this procedure could take the upper hand in the treatment during the next few decades.
\end{abstract}

\section{Keywords}

Hypertrophic cardiomyopathy, Radiofrequency ablation, Alcohol septal ablation, Surgical myectomy

\section{Introduction}

Hypertrophic cardiomyopathy (HCM) is a common cardiac disease that affects 1 in every 500 persons worldwide. It is an autosomal dominant inherited disease characterized by otherwise unexplained asymmetrical hypertrophy of the myocardium most often occurring in the sub-aortic region [1-4].

Hypertrophic Cardiomyopathy mainly manifests itself as left ventricular (LV) hypertrophy. This hypertrophy leads to resting as well as provocative left ventricular outflow tract (LVOT) obstruction with a peak gradient of $\geq 30 \mathrm{mmHg}$. This is present in $20-30 \%$ of subjects at rest and in up to $70 \%$ with exercise provocation. This obstruction leads to dyspnea, chest pain, atrial fibrillation, heart failure and even sudden death [5-9].
Surgical myectomy and alcohol septal ablation (ASA) have been over the last few decades the gold standard of treatment. However, the complications of these interventions in terms of trauma, safety, and efficacy call for a minimally invasive, potentially safer, and more efficacious strategy $[10,11]$.

Therefore, radiofrequency ablation was first implemented by Lawrenz, et al. in the year 2004 on a 45 -yearold male patient who suffered from severe symptoms of hypertrophic obstructive cardiomyopathy (HOCM). This resulted in massive decrease in the LVOT gradient at rest and after provocation (by $54 \mathrm{mmHg}$ and $66 \mathrm{mmHg}$ ) respectively [12]. However a similar idea was first postulated by Dalvi B in the year 1994 as he suggested that the causation of a left bundle branch block could result in diminution or elimination of left ventricular outflow tract gradients [13]. Radiofrequency septal ablation has been implemented till this date on 108 patients in 8 clinical trials and 2 case reports done by Lawrenz, et al. (2004) and Riedelbauchova, et al. (2013) [14].

Radiofrequency septal ablation has also been tried on 6 sheep by Liu, et al. in the year 2019. The animals were positioned in the right lateral position and under echocardiographic guidance a radiofrequency ablator was introduced through the right ventricle to the interventricular septum. It was placed in the mid-wall of the basal inter ventricular septum. The ablation is terminated when $2 / 3$ of the thickness of the septum was ablated.

This technique resulted in an immediate significant increase in the left ventricular outflow tract gradient due to the edema from the ablation process and then de- 
Table 1: Advantages and disadvantages of various techniques.

\begin{tabular}{|c|c|c|c|}
\hline & ASA [16] & Surgical myectomy [16] & RFA [17-19] \\
\hline Advantages & $\begin{array}{ll}\text { - } & \text { Less invasive } \\
\text { - } & \text { Avoidance of sternotomy } \\
\text { - } & \text { Shorter hospital stay } \\
\text { - } & \text { Lower risk of stroke }\end{array}$ & 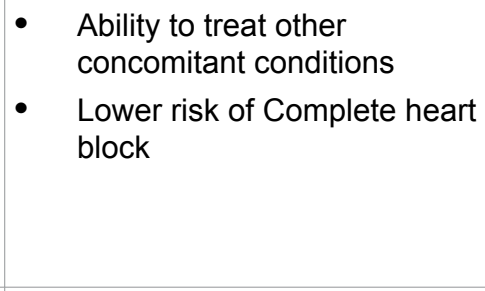 & $\begin{array}{ll}\text { - } & \text { Less invasive } \\
\text { - } & \text { Avoidance of sternotomy } \\
\text { - } & \text { Shorter hospital stay } \\
\text { - } & \text { Lower risk of stroke } \\
\text { - } & \text { Lower risk of } \mathrm{CHB} \\
\text { - } & \text { Lof } \mathrm{BBB}\end{array}$ \\
\hline Disadvantages & $\begin{array}{ll}\text { - } & \text { Requires suitable coronary anatomy } \\
\text { - } & \text { High rate of bundle branch block } \\
\text { - } & \text { High rate of } \mathrm{CHB} \\
\text { - } & \text { Potentially arrhythmogenic }\end{array}$ & $\begin{array}{ll}\text { - } & \text { Open heart surgery with } \\
\text { - } & \text { Hypass } \\
\text { - } & \text { High rate of LBBB } \\
\text { - } & \text { Limited availability of } \\
\text { - } & \text { expertise } \\
\text { Side effects of surgeries }\end{array}$ & $\begin{array}{ll}\text { - } & \text { High cost } \\
\text { - } & \text { Limited data due to } \\
\text { minimal amount of trials }\end{array}$ \\
\hline
\end{tabular}

creased once again significantly 2 weeks to 12 months after the procedure (from 88 to $11 \mathrm{mmHg}$ ). All animals tolerated and completed the full $5 \mathrm{~min}$ of ablation and survived the percutaneous intramyocardial septal radiofrequency ablation (PIMSRA) procedure. No severe complications, such as ventricular fibrillation, inter ventricular septum perforation, or pericardial tamponade, were observed during the 6 months of follow up. Mild and self-limited pericardial effusion occurred in 1 animal and resolved spontaneously 2 days following the procedure [15].

This new technique (radiofrequency ablation) showed several advantages as compared to the previously done Surgical myectomy and alcohol septal ablation (ASA). These advantages could be observed in (Table 1).

\section{Preprocedure}

Complete history must be taken to detect the NYHA classification. Most patients who have undergone the procedure were grade III. Moreover, walk test was done to detect the maximum distance that could be achieved with the hypertrophied septum. Patients had to undergo an Echocardiography under resting conditions and Cardiopulmonary exercise testing is performed using a bicycle ergometer protocol with $10 \mathrm{~W}$ minutely increments to detect the gradient across the left ventricular outflow tract. The baseline and post procedural characteristics of these patients could be seen in Table 2 .

Other invasive preoperative techniques have been implemented before the radiofrequency septal ablation. Some of the patients have undergone a transesophageal echo to detect any abnormalities in the left atrium and for the presence of thrombi to avoid having post procedural ischemic changes. Other investigations involved the measurement of the LVOT gradients at rest and post-extrasystolic invasively using a $5 \mathrm{Fr}$ catheter with the aid of coronary angiography.

Before performing the radiofrequency septal ablation, institutions had to approve performing this proce- dure. These institutions included: The local ethics committee of the University of Muenster, Muenster, Germany - by the research and development board of Liverpool Heart and Chest Hospital - the Institutional Review Board at North Mississippi Health Services [18-24].

\section{Procedure}

All procedures are performed under general anaesthesia, usually using propofol and atracurium followed by isoflurane to facilitate the control of respiratory and patient motion. Furthermore, radiolucent defibrillator pads are routinely placed for remote defibrillation Vasoconstrictors are used in order to maintain the blood pressure and avoid the sudden drop in the blood pressure in order to maintain the organ perfusion. An arterial sheath is usually placed in the femoral artery for real-time blood pressure monitoring. It could also be used as a potential access for ablation via a retrograde trans-aortic approach if needed.

The catheter is inserted through the right femoral vein advanced over a guide wire and manipulated through the inferior vena cava, right atrium and into the right ventricle (RV) inlet. In addition temporary pacing electrodes are placed in the right ventricle and right atrium via the femoral vein. A phased array probe could be used to produce high quality images of the right ventricle, left ventricle, and aorta. Endocardial borders, papillary muscles, the proximal His bundle and its' relations to the LVOT, aortic cusps, and coronary ostia are precisely marked and then transferred into the mapping systems such as (CARTOw system - the LocaLisa mapping or the NavX system). A quadripolar diagnostic catheter is initially placed across the tricuspid valve for His bundle localization The structural borders were manually contoured and recorded in the traditional method at the end of diastole. A new high density, multilevel map was then created of the multiple regions of contact of the anterior mitral valve leaflet and the hypertrophied septum. Owing to physiological restrictions, (the contact is only during systole), this map is created in systole. 


\begin{tabular}{|c|c|c|c|c|c|c|c|c|c|}
\hline 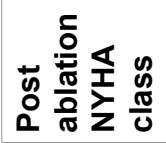 & $z$ & $z$ & $\begin{array}{l}1 \\
0 \\
+1 \\
0 \\
-\end{array}$ & $\begin{array}{l}\infty \\
0 \\
+1 \\
0 \\
-\end{array}$ & $\begin{array}{l}0 \\
0 \\
+1 \\
+1 \\
\infty \\
+\end{array}$ & $\begin{array}{l}\infty \\
0 \\
+1 \\
\infty \\
+\end{array}$ & $\begin{array}{l}0 \\
0 \\
+1 \\
+ \\
\vdots\end{array}$ & $\stackrel{\circ}{\circ}$ & $\begin{array}{l}0 \\
0 \\
+1 \\
m \\
? \\
?\end{array}$ \\
\hline 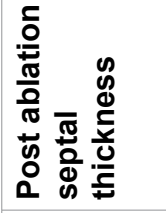 & $z$ & $z$ & $\begin{array}{l}\dot{v} \\
\dot{m} \\
+1 \\
\dot{\sigma}\end{array}$ & $\mathbf{z}$ & \begin{tabular}{l}
0 \\
\multirow{1}{*}{} \\
+1 \\
$\infty$ \\
0 \\
0
\end{tabular} & @̊ & $z$ & $\begin{array}{l}0 \\
\stackrel{N}{1} \\
+1 \\
\circ \\
\dot{+}\end{array}$ & $\begin{array}{l}\stackrel{\sigma}{r} \\
+1 \\
\stackrel{+}{v} \\
\stackrel{\sim}{\leftarrow}\end{array}$ \\
\hline 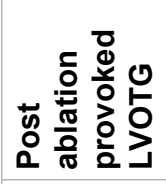 & $z$ & $z$ & 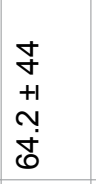 & $z$ & $\begin{array}{l}m \\
\infty \\
+1 \\
m \\
\infty \\
N\end{array}$ & $\begin{array}{l}\hat{0} \\
0 \\
+1 \\
0 \\
\dot{N}\end{array}$ & $z$ & $\begin{array}{l}0 \\
\dot{0} \\
+1 \\
0 \\
\stackrel{\rho}{N}\end{array}$ & 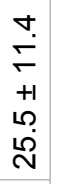 \\
\hline 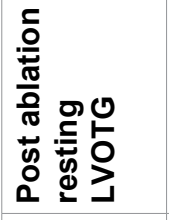 & $\begin{array}{l}\stackrel{9}{i} \\
\text { +1 } \\
\stackrel{+}{\dot{\omega}} \\
\stackrel{N}{ }\end{array}$ & $\begin{array}{l}\tilde{N} \\
\stackrel{N}{+1} \\
\tilde{N}\end{array}$ & $\begin{array}{l}N \\
+1 \\
1 \\
0 \\
\stackrel{N}{N}\end{array}$ & 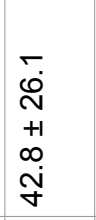 & 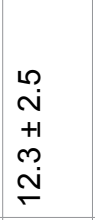 & $\begin{array}{l}1 \\
i n \\
+1 \\
0 \\
0 \\
0\end{array}$ & $\begin{array}{l}0 \\
\dot{0} \\
+ \\
+1 \\
+ \\
\dot{0}\end{array}$ & $\begin{array}{l}0 \\
10 \\
+1 \\
0 \\
\check{r} \\
\leftarrow\end{array}$ & $\begin{array}{l}\hat{1} \\
10 \\
+1 \\
\infty \\
\check{\Gamma}\end{array}$ \\
\hline 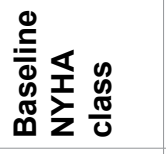 & $z$ & $z$ & 임 & 임 & 임 & $\stackrel{\circ}{\ddot{m}}$ & $\stackrel{\circ}{\text { m. }}$ & $\begin{array}{l}+ \\
0 \\
+1 \\
0 \\
i\end{array}$ & $\begin{array}{l}\stackrel{+}{0} \\
+ \\
+1 \\
\infty \\
i\end{array}$ \\
\hline 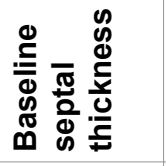 & $z$ & $z$ & $\begin{array}{l}\hat{n} \\
+1 \\
0 \\
\tilde{N}\end{array}$ & $z$ & $\begin{array}{l}\stackrel{\rho}{r} \\
+1 \\
m \\
\infty \\
\infty\end{array}$ & $\stackrel{\circ}{\grave{N}}$ & $\begin{array}{l}L \\
\dot{+} \\
+1 \\
\infty \\
\dot{\sigma} \\
\stackrel{-}{-}\end{array}$ & $\begin{array}{l}0 \\
\dot{+} \\
+1 \\
0 \\
\stackrel{\sim}{N}\end{array}$ & $\begin{array}{l}0 \\
\stackrel{1}{ } \\
+1 \\
0 \\
\stackrel{\sim}{N}\end{array}$ \\
\hline 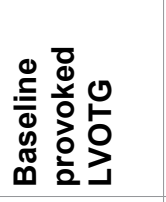 & $z$ & $z$ & $\begin{array}{l}\hat{m} \\
+1 \\
10 \\
\hat{N} \\
\stackrel{0}{1}\end{array}$ & $z$ & $\begin{array}{l}0 \\
0 \\
m \\
+1 \\
10 \\
\text { mं }\end{array}$ & $\begin{array}{l}0 \\
0 \\
0 \\
+1 \\
\sim \\
0 ் \\
\stackrel{m}{-}\end{array}$ & $z$ & $\begin{array}{l}0 \\
0 \\
e \\
+1 \\
0 \\
\\
\mp\end{array}$ & $\begin{array}{l}\infty \\
\infty \\
+1 \\
\infty \\
\infty \\
+ \\
+\end{array}$ \\
\hline 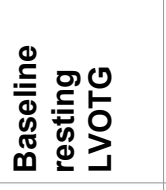 & $\begin{array}{l}\infty \\
i \\
+1 \\
+1 \\
\hat{\infty} \\
\infty\end{array}$ & $\begin{array}{l}\hat{N} \\
+1 \\
0 \\
\dot{8} \\
8\end{array}$ & $\begin{array}{l}\text { O } \\
+1 \\
+ \\
N\end{array}$ & $\begin{array}{l}\infty \\
\dot{+} \\
+1 \\
0 \\
\infty \\
\infty\end{array}$ & $\begin{array}{l}0 \\
0 \\
0 \\
+1 \\
m \\
\dot{0}\end{array}$ & $\begin{array}{l}n \\
0 \\
\infty \\
+1 \\
1 \\
0 \\
0\end{array}$ & $\begin{array}{l}\infty \\
\tilde{N} \\
n \\
+1 \\
0 \\
\tilde{0} \\
0\end{array}$ & \begin{tabular}{l}
0 \\
\multirow{N}{N}{} \\
+1 \\
0 \\
$\infty$ \\
$\infty$
\end{tabular} & $\begin{array}{l}\stackrel{+}{\sim} \\
m \\
+1 \\
m \\
\\
\infty\end{array}$ \\
\hline 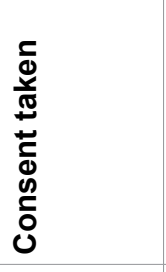 & 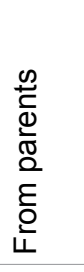 & 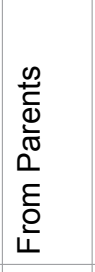 & 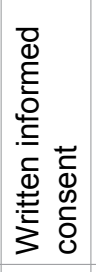 & 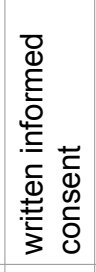 & 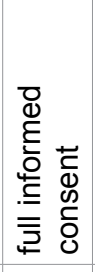 & 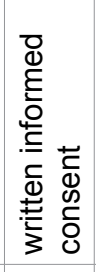 & 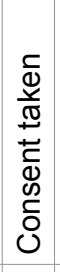 & 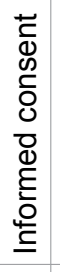 & 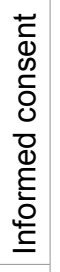 \\
\hline 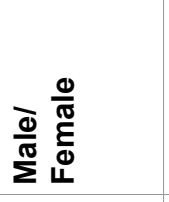 & 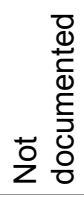 & $\frac{m}{\frac{m}{\sigma}}$ & 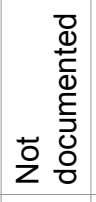 & $\frac{N}{10}$ & $\stackrel{\Xi}{\rightleftharpoons}$ & $\frac{\gamma}{\gamma}$ & $\stackrel{m}{\sim}$ & 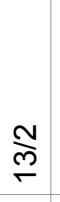 & $\Sigma_{\infty}$ \\
\hline 完 & $\mp$ & 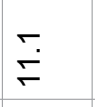 & तें & $\stackrel{\sim}{\mathscr{q}}$ & $\underset{10}{0}$ & ชิ & $\bar{\sigma}$ & $\begin{array}{l}m \\
\stackrel{+}{+}\end{array}$ & ॄ் \\
\hline 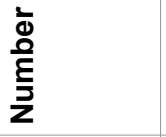 & $m$ & లె & $\stackrel{\text { g }}{\square}$ & 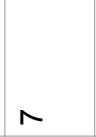 & 10 & $\mp$ & ما & $\stackrel{10}{\leftarrow}$ & $\sigma$ \\
\hline 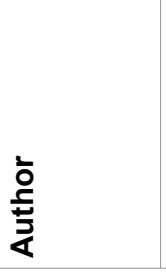 & 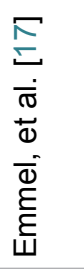 & 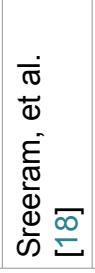 & 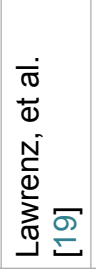 & 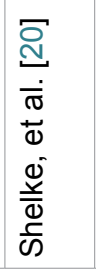 & 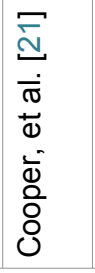 & 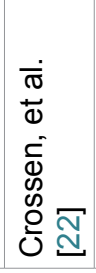 & 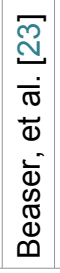 & 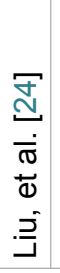 & 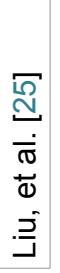 \\
\hline
\end{tabular}

Retrograde aortic route was used to access the left ventricle as the extent of narrowing of the outflow tract probably restricts the ability to advance the mapping or ablation catheter antegrade through the mitral valve into the most superior portions of the outflow tract. After introduction of the ablation catheter to the left ventricle, the patient is placed on intravenous heparin. Intravenous heparin is administered to keep activated clotting time at about (200s). The His conduction tissue, left bundle, left anterior and posterior fascicles were directly mapped and localized on the mapping system, and their positions noted in relation to the systolic anterior motion-septal contact area. Once completed, the models are field-scaled in the mapping system either the thickest or the most apical portion of the septum are marked in the mapping system and targeted for the initial lesion.

Radiofrequency energy is then delivered. A combination of mapping system images and intracardiac echo navigation is used in order to overcome the specialized conduction tissue (e.g. left bundle/fascicles) is avoided. Radiofrequency ablation powers of 50-60W limited to temperatures (45 degrees Celsius to 60 degrees Celsius) are used with saline irrigation at $30 \mathrm{~mL} / \mathrm{min}$. A 2 min application times are used per lesion and an average of 43 lesions are applied in most of the patients.

The procedural endpoints were marked by complete coverage of systolic anterior motion (SAM) of the mitral valve-septal contact area as well as reduction in the septal thickness. Myocardial oedema could be seen up to $10 \mathrm{~mm}$ from the endocardial LV surface after the stoppage of the radiofrequency energy delivery. Resolution of the left ventricular outflow tract gradient could not be used due to the immediate paradoxical increase after the radiofrequency ablation. Anticoagulation is reversed at the end using intravenous protamine [17-23,25].

\section{Results}

\section{Symptomatic results}

Patients showed significant improvement of their complaints due to reduction of the left ventricular outflow tract gradient. Chest pain and angina symptoms are reduced to class CCS 1-2. The walking distance in the six-minute walking test showed an improvement in most patients (by approximately $34 \%$ improvement). Most patients recover uneventfully.

\section{Laboratory investigations}

Mean peak troponin levels were increased 
Table 3: Follow up period and complications of patients.

\begin{tabular}{|l|l|l|l|}
\hline Author & Year & Follow Up Period & Complications \\
\hline Emmel, et al. [17] & 2005 & 1.5 months & One VF \\
\hline Sreeram, et al. [18] & 2011 & 48 months & $\begin{array}{l}\text { One paradoxical increase in LVOTG [death], 2 } \\
\text { permanent pacemaker, 2 VF, One Superficial burn } \\
\text { from earthing plate, One groin hematoma }\end{array}$ \\
\hline Lawrenz, et al. [19] & 2011 & 6 months & One tamponade, 4 permanent pacemaker \\
\hline Shelke, et al. [20] & 2014 & 12 months & One pulmonary edema \\
\hline Cooper, et al. [21] & 2015 & 6 months & $\begin{array}{l}\text { One retroperitoneal haemorrhage [death] }, \text { One } \\
\text { pulmonary edema [LVOTG] increased }\end{array}$ \\
\hline Crossen, et al. [22] & 2016 & 12 months & $\begin{array}{l}\text { One tamponade, one pulmonary congestion, 2 } \\
\text { permanent pacemaker }\end{array}$ \\
\hline Beaser, et al. [23] & 2018 & 1.3 months & Not documented \\
\hline Liu, et al. [24] & 2018 & 6 months & 9 patients ventricular ectopic beats, One tamponade \\
\hline Liu, et al. [25] & 2019 & 6 months & Not documented \\
\hline
\end{tabular}

Abbreviations: VF: Ventricular Fibrillation; LVOTG: Left Ventricular Outflow Tract Gradient.

immediately post operative due to the affection of the cardiac muscle. However it normalizes in most patients within 24 hours.

\section{Echocardiographic parameters}

Echocardiogram is performed during the follow up period in all patients. Average peak resting and exercise induced gradients improved significantly in most patients.

\section{Complications post procedure}

Complications ranged from mild complications such as groin hematoma and superficial burns from the earthing plate to severe complications such as retroperitoneal haemorrhage and cardiovascular collapse following sheath removal, this requires urgent surgical repair of the femoral artery. However, that has lead to mesenteric ischaemia in a single patient and ultimately to death. In addition ventricular fibrillation during radiofrequency energy application is observed, this complication is associated with prolonged catheter manipulation in the left ventricle and it requires DC cardioversion. In addition, acute pericardial tamponade during right ventricle ablation caused by perforation of the right ventricular pacing lead, requiring surgical revision, was also noted.

Other complications included: paradoxical increase in the left ventricular outflow tract gradient immediately following ablation due to tissue oedema resulting in increase in the back pressure and pulmonary oedema. This complication could be managed by reintubation, intravenous dexamethasone administration, and right ventricular apical pacing in order to reduce the gradient.

The development of complete AV block requiring a permanent pacemaker implantation is one of the disadvantages of radiofrequency catheter ablation. This could be prevented by lowering the power delivered and the irrigation rates if radiofrequency energy has to be delivered close to $\mathrm{AV}$ node and bundle of His.
Follow up period and complications could be seen in Table 3 [26,27].

\section{Conclusion}

Although further study is still required as radiofrequency septal ablation was tried only on 108 patients as a treatment modality for hypertrophic cardiomyopathy, it represents a safe treatment approach for severe, symptomatic hypertrophic cardiomyopathy. It leads to sustained improvement in exercise capacity, persistent reduction in LVOT gradient, and sustained improvement in the cardiac functions. It allows significant and sustained gradient reduction and symptomatic improvement of patients with severe hypertrophic cardiomyopathy $[26,27]$.

\section{References}

1. Semsarian C, Ingles J, Maron MS, Maron BJ (2015) New perspectives on the prevalence of hypertrophic cardiomyopathy. J Am Coll Cardiol 65: 1249-1254.

2. Maron BJ, McKenna WJ, Danielson GK, Kappenberger LJ, Kuhn HJ, et al. (2003) American College of Cardiology/ European Society of Cardiology clinical expert consensus document on hypertrophic cardiomyopathy. A report of the American College of Cardiology Foundation Task Force on Clinical Expert Consensus Documents and the European Society of Cardiology Committee for Practice Guidelines. J Am Coll Cardiol 42: 1687-1713.

3. Tuohy CV, Kaul S, Song HK, Nazer B, Heitner SB (2020) Hypertrophic cardiomyopathy: The future of treatment. Eur $\mathrm{J}$ Heart Fail.

4. Gersh BJ, Maron BJ, Bonow RO, Dearani JA, Fifer MA, et al. (2011) 2011 ACCF/AHA Guideline for the diagnosis and treatment of hypertrophic cardiomyopathy. J Am Coll Cardiol 58: 2703-2738.

5. Elliott PM, Anastasakis A, Borger MA, Borggrefe M, Cecchi F, et al. (2014) 2014 ESC guidelines on diagnosis and management of hypertrophic cardiomyopathy: The Task Force for the Diagnosis and Management of Hypertrophic Cardiomyopathy of the European Society of Cardiology (ESC). Eur Heart J 35: 2733-2779.

6. Maron MS, Olivotto I, Betocchi S, Casey SA, Lesser JR, et 
al. (2003) Effect of left ventricular outflow tract obstruction on clinical outcome in hypertrophic cardiomyopathy. $\mathrm{N} \mathrm{Engl}$ J Med 348: 295-303.

7. Elliott P, Gimeno J, Tomé M, McKenna W (2006) Left ventricular outflow tract obstruction and sudden death in hypertrophic cardiomyopathy. Eur Heart J 27: 3073-3074.

8. Gimeno JR, Tomé-Esteban M, Lofiego C, Hurtado J, Pantazis A, et al. (2009) Exercise-induced ventricular arrhythmias and risk of sudden cardiac death in patients with hypertrophic cardiomyopathy. Eur Heart J 30: 2599-2605.

9. Veselka J, Anavekar NS, Charron P (2017) Hypertrophic obstructive cardiomyopathy. Lancet 389: 1253-1267.

10. Desai MY, Bhonsale A, Smedira NG, Naji P, Thamilarasan M, et al. (2013) Predictors of long-term outcomes in symptomatic hypertrophic obstructive cardiomyopathy patients undergoing surgical relief of left ventricular outflow tract obstruction. Circulation 128: 209-216.

11. Rigopoulos AG, Seggewiss H (2016) Twenty years of alcohol septal ablation in hypertrophic obstructive cardiomyopathy. Curr Cardiol Rev 12: 285-296.

12. Lawrenz T, Kuhn H (2004) Endocardial radiofrequency ablation of septal hypertrophy. A new catheter-based modality of gradient reduction in hypertrophic obstructive cardiomyopathy. Z Kardiol 93: 493-499.

13. Dalvi B (1994) Percutaneous radiofrequency ablation of the left bundle branch: An alternative modality of treatment for patients with hypertrophic obstructive cardiomyopathy. Med Hypotheses 43: 141-144.

14. Riedlbauchová L, Janoušek J, Veselka J (2013) Ablation of hypertrophic septum using radiofrequency energy: An alternative for gradient reduction in patient with hypertrophic obstructive cardiomyopathy? J Invasive Cardiol 25: E128E132.

15. Liu F, Fu J, Hsi D, Sun C, He G, et al. (2020) Percutaneous intramyocardial septal radiofrequency ablation for interventricular septal reduction: An ovine model with 1-year outcomes. Cardiology 145: 53-62.

16. Fassa A, Sigwart $U$ (2010) Septal reduction therapy for hypertrophic cardiomyopathy. The Journal of Cardiovascular Medicine 13: 228-234.

17. Emmel M, Sreeram N, deGiovanni JV, Brockmeier K (2005) Radiofrequency catheter septal ablation for hypertrophic obstructive cardiomyopathy in childhood. Z Kardiol 94: 699-703.
18. Sreeram N, Emmel M, de Giovanni JV (2011) Percutaneous radiofrequency septal reduction for hypertrophic obstructive cardiomyopathy in children. J Am Coll Cardiol 58: 2501-2510.

19. Lawrenz T, Borchert B, Leuner C, Bartelsmeier M, Reinhardt J, et al. (2011) Endocardial radiofrequency ablation for hypertrophic obstructive cardiomyopathy: Acute results and 6 months' follow-up in 19 patients. J Am Coll Cardiol 57: $572-576$.

20. Shelke AB, Menon R, Kapadiya A, Yalagudri S, Saggu D, et al. (2016) A novel approach in the use of radiofrequency catheter ablation of septal hypertrophy in hypertrophic obstructive cardiomyopathy. Indian Heart J 68: 618-623.

21. Cooper RM, Shahzad A, Hasleton J, Digiovanni J, Hall MC, et al. (2016) Radiofrequency ablation of the interventricular septum to treat outflow tract gradients in hypertrophic obstructive cardiomyopathy: A novel use of CARTOSound $囚$ technology to guide ablation. Europace 18: 113-120.

22. Crossen K, Jones M, Erikson C (2016) Radiofrequency septal reduction in symptomatic hypertrophic obstructive cardiomyopathy. Heart Rhythm 13: 1885-1890.

23. Beaser AD, Sobacki J, Aziz Z (2018) Targeted radiofrequency septal ablation to reduce outflow tract gradient in symptomatic hypertrophic obstructive cardiomyopathy: Initial feasibility cohort. Heart Rhythm 15: S644-S645.

24. Liu L, Li J, Zuo L, Zhang J, Zhou M, et al. (2018) Percutaneous intramyocardial septal radiofrequency ablation for hypertrophic obstructive cardiomyopathy. J Am Coll Cardiol 72: 1898-1909.

25. Liu LW, Zuo L, Zhou MY, Li J, Zhou XD, et al. (2019) Efficacy and safety of transthoracic echocardiography-guided percutaneous intramyocardial septal radiofrequency ablation for the treatment of patients with obstructive hypertrophic cardiomyopathy. Zhonghua Xin Xue Guan Bing Za Zhi 47: 284-290.

26. Poon SS, Cooper RM, Gupta D (2016) Endocardial radiofrequency septal ablation - A new option for non-surgical septal reduction in patients with hypertrophic obstructive cardiomyopathy (HOCM)?: A systematic review of clinical studies. Int J Cardiol 222: 772-774.

27. Yang $H$, Yang $Y$, Xue $Y$, Luo S (2020) Efficacy and safety of radiofrequency ablation for hypertrophic obstructive cardiomyopathy: A systematic review and meta-analysis. Clin Cardiol. 